\title{
Cross-cultural adaptation and reliability testing of Polish adaptation of the European Heart Failure Self-care Behavior Scale (EHFScBS)
}

This article was published in the following Dove Press journal:

Patient Preference and Adherence

31 October 2014

Number of times this article has been viewed

\author{
Izabella Uchmanowicz' \\ Maria Łoboz-Rudnicka ${ }^{2}$ \\ Tiny Jaarsma ${ }^{3}$ \\ Krystyna Łoboz-Grudzień ${ }^{1,2}$ \\ 'Department of Clinical Nursing, \\ Wrocław Medical University, Wrocław, \\ Poland; ${ }^{2}$ Department of Cardiology, \\ T Marciniak Memorial Hospital, \\ Wrocław, Poland; ${ }^{3}$ Department \\ of Social and Welfare Studies, \\ University of Linköping, Linköping, \\ Sweden
}

Correspondence: Izabella Uchmanowicz Department of Clinical Nursing, Wrocław Medical University, ul Bartla 5 , Wrocław, Poland

Tel +48717841824

Fax +48 7I 3459324

Email izabella.uchmanowicz@umed.wroc.pl
Background: Development of simple instruments for determination of self-care levels in heart failure (HF) patients is a subject of ongoing research. One such instrument, gaining growing popularity worldwide, is the European Heart Failure Self-care Behavior Scale (EHFScBS). The aim of this study was to adapt and to test reliability of the Polish version of EHFScBS.

Method: A standard guideline was used for translation and cultural adaptation of the English version of EHFScBS into Polish. The study included 100 Polish HF patients aged between 24 and 91 years, among them 67 men and 33 women. Cronbach's alpha was used for analysis of the internal consistency of EHFScBS.

Results: Mean total self-care score in the study group was $34.2 \pm 8.1$ points. Good or satisfactory level of self-care were documented in four out of 12 analyzed EHFScBS domains. Cronbach's alpha for the entire questionnaire was 0.64 . The value of Cronbach's alpha after deletion of specific items ranged from 0.55 to 0.65 .

Conclusion: Polish HF patients present significant deficits of self-care, which are to a large extent associated with inefficacy of the public health care system. Apart from cultural characteristics, the socioeconomic context of the target population should be considered during language adaptation of EHFScBS, as well as during interpretation of data obtained with this instrument. A number of self-care-related behaviors may be optimized as a result of appropriate educational activities, also those offered by nursing personnel.

Keywords: self-care, European Heart Failure Self-care Behavior Scale, internal consistency, reliability

\section{Introduction}

Growing prevalence of cardiovascular diseases, especially heart failure (HF), as well as the resultant increase in therapeutic costs, necessitates optimization of management of patients affected with these conditions. HF is estimated to affect $1 \%-2 \%$ of the adult population in developed countries and constitutes one of the most frequent causes of hospitalization due to cardiovascular conditions. Frequent hospitalizations due to HF are associated with worse quality of life and poorer prognosis. As with any other chronic condition, HF raises negative emotions and causes problems in physical, mental, and social functioning. This frequently results in limitations in the daily living activities and enforces resignation from previously fulfilled duties. Implementation of a holistic care model, according to which a patient is actively involved in the therapeutic process, rather than only being a subject of medical services, is one postulated solution of the problem in question. However, development of patient health awareness is required to achieve this objective, along with related educational activities. ${ }^{1,2}$ Many studies 
have showed that systematic education of HF patients plays a significant role in the tertiary prevention of this condition, which is reflected by a decrease in decompensation and rehospitalization rates. ${ }^{1,3}$ Moreover, the effectiveness of the educational activities turned out to be higher if the latter were oriented on self-care promotion. In the case of HF patients, the term "self-care" refers to appropriate use of prescribed medications, lifestyle modification, including dietary habits and physical activity level, and the ability to recognize and respond to early signs of decompensation..$^{4-7}$

Despite being seemingly easy, implementation of the abovementioned educational activities faces a number of obstacles. Although the issue of health educators should be solved by the involvement and appropriate preparation of cardiology nurses in this role, achieving persistent and objective educational effects is still problematic. This at least partially results from the characteristics of HF patients themselves, as this group comprises a number of older individuals, who live alone, and possess limited cognitive resources and memory. Consequently, apart from the process of education itself, monitoring of its short- and long-term outcomes and implementation of intervention in case of any greater deficits in self-care-related knowledge also remain vital issues. ${ }^{6,8,9}$

Consequently, the development of simple instruments for the determination of self-care levels in HF patients is a subject of research. One such instrument, gaining growing popularity worldwide, is the European Heart Failure Self-care Behavior Scale (EHFScBS). ${ }^{9}$ This questionnaire was developed on the basis of the theoretical construct of self-care by Orem. ${ }^{10}$ In its present version, EHFScBS includes 12 questions related to various aspects of self-care, among them daily control of weight, level of physical activity, use of low-sodium diet, amount of ingested fluids, self-monitoring, and appropriate reaction to potential symptoms of decompensation. ${ }^{9}$ The instrument has passed validation and psychometric verification in many populations and culture groups and was a subject of many translations and adaptations. ${ }^{11-16}$

Similar to other developed countries, HF constitutes the main cause of hospitalization and mortality among Polish patients, especially in the elderly. However, contrary to Western communities, it was only recently that the role of holistic care to HF patients was realized in Poland. ${ }^{17}$ This delay is inter alia reflected by the lack of Polish instruments for psychological and social diagnosis of patients with this condition, including their demand for educational activity. In order to fill this gap, we decided to develop a Polish adaptation of EHFScBS and to test its reliability in a group of HF patients. The aim of this paper is to present the results of the reliability testing.

\section{Materials and methods Questionnaire}

The EHFScBS questionnaire contains 12 statements regarding three theoretical aspects of self-care behaviors: complying with regimen (control of weight, fluid restriction, low-sodium diet, medication adherence, flu vaccinations), adapting activities (rest, physical activity), and seeking of help in the case of symptoms of potential decompensation (shortness of breath, increased fatigue, lower limb swelling, considerable weight gain in a short period of time). The respondent scores a number of statements on a 5-item Likert scale (from 1 - "I completely agree" to 5 - "I don't agree at all"). The total score, being a sum of all the 12 answers, can range from 12 to 60 points, with lower values corresponding to better self-care of the given individuals. Moreover, the quality of self-care in specific domains represented by individual statements can be determined, with scores of 1-2 corresponding to high and scores of 3-5 to low self-care levels.

\section{Polish adaptation of EHFScBS}

A standard guideline ${ }^{18}$ was used for the translation and cultural adaptation of the English version of EHFScBS ${ }^{9}$ into Polish (Table 1). After obtaining permission from the authors of the original instrument, it was independently translated into Polish by two translators specialized in biomedical projects. Subsequently, both translations were assessed by a panel of ten competent referees for the form and content of the individual statements and for appropriateness and clarity of the questionnaire's instructions. The panel consisted of five geriatric and cardiovascular nurses, two physicians (one gerontologist and one cardiologist), and three specialists in health psychology. All the panel members had over 10 years of experience with working with cardiac patients. Eventually, when the referees reached consensus on the final version of translation, it was subjected to a back-translation process and sent to the authors of the original instrument for their approval. Subsequently, the preliminary adaptation was subjected to a preliminary study in a group of 30 randomly chosen patients. Eventually, the final Polish version of EHFScBS was obtained and subjected to the hereby reported validation study (Table 1).

\section{Patients}

The study, conducted at the Specialist Hospital in Wrocław between May 2013 and January 2014, included 100 patients with stable HF. The participants filled in the questionnaire during routine control visits. The only exclusion criteria were cognitive deficits, communication barriers (eg, deafness, blindness), or problems with manual dexterity. The sample size was selected based on literature data, according 
Table I Original version of EHFScBS and its Polish adaptation

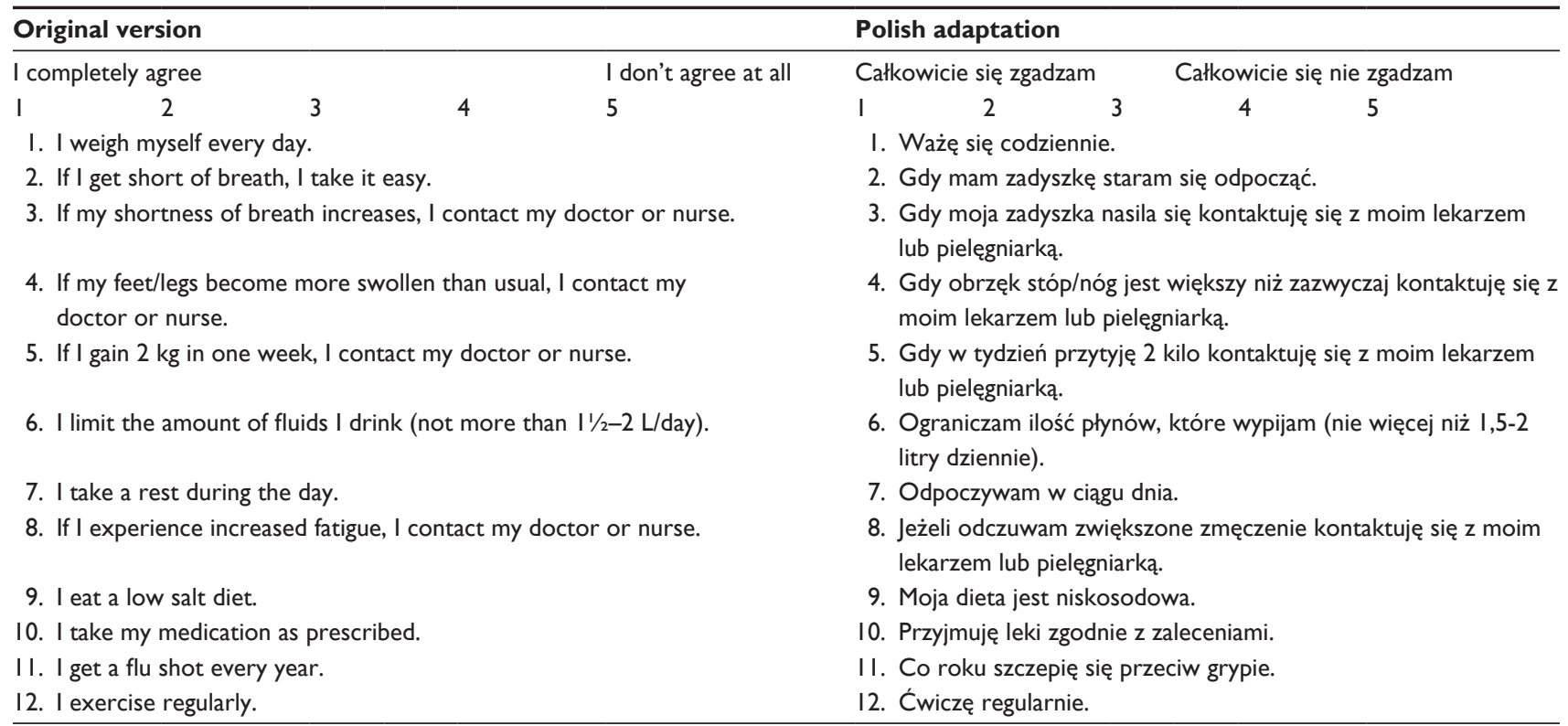

Notes: Adapted from Jaarsma T, Arestedt KF, Martensson J, Dracup K, Stromberg A. The European Heart Failure Self-care Behaviour scale revised into a nine-item scale (EHFScB-9): a reliable and valid international instrument. Eur J Heart Fail. 2009; I I(1):99-105. Published on behalf of the European Society of Cardiology. All rights reserved. Copyright (C) 2009 Jaarsma T, Arestedt KF, Martensson J, Dracup K, Stromberg A. ${ }^{24}$

Abbreviation: EHFScBS, European Heart Failure Self-care Behavior Scale.

to which the minimum number of participants taking part in a validation study should be at least five times larger than the number of variables being analyzed; ${ }^{19}$ consequently, validation of EHFScBS should be based on examination of at least 60 patients $(5 \times 12$ statements). All the participants gave their written informed consent for participation in the study, and its protocol was approved by the Local Bioethical Committee at Wrocław Medical University (decision no Nbr 459/2013).

\section{Statistical analysis}

Statistical analysis was conducted with Statistica 10 package (StatSoft, Inc., Tulsa, OK, USA). Normal distribution of continuous variables was verified with the Kolmogorov-Smirnov test, and their statistical characteristics were expressed as the arithmetic means \pm standard deviation (SD), medians, and interquartile ranges (IQR). Categorical variables were expressed as absolute frequencies (n). Cronbach's alpha was used for analysis of internal consistency.

\section{Results}

The study included 67 men and 33 women aged between 24 and 91 years. The vast majority of the participants suffered from New York Heart Association (NYHA) class II or III HF. Detailed characteristics of the examined patients are presented in Table 2.

The mean total self-care score in the study group was $34.2 \pm 8.1$ points. Good or satisfactory level of self-care (mean values of 1 or 2 on the Likert-type scale) were documented in four out of 12 analyzed domains: rest (statements no 2 and 7), medication adherence (statement no 8), and low-sodium diet (statement no 9). The scores of the remaining statements pointed to low levels of self-care in their respective domains. The highest fractions of unsatisfactory answers referred to yearly flu vaccination ( $n=82)$, controlling weight on a daily basis $(n=76)$, and informing a doctor or nurse on sudden weight gain $(n=75)$. Detailed characteristics of the scores

Table 2 Demographic and clinical characteristics of the study participants

\begin{tabular}{ll}
\hline Characteristics & Value $(\mathrm{n}=1 \mathbf{0 0})$ \\
\hline Age (years) & $67.5(60-76.5)$ \\
Sex & \\
$\quad$ Male & $\mathrm{n}=67$ \\
$\quad$ Female & $\mathrm{n}=33$ \\
Education (years) & $10(8-12)$ \\
Left ventricular ejection fraction (\%) & $35(30-45)$ \\
NYHA class & \\
I & $\mathrm{n}=1$ \\
II & $\mathrm{n}=44$ \\
III & $\mathrm{n}=54$ \\
IV & $\mathrm{n}=1$ \\
Time from HF diagnosis (years) & $2(I-6)$ \\
Medication & \\
Diuretics & $\mathrm{n}=97$ \\
Beta blockers & $\mathrm{n}=96$ \\
ACEi/ARB & $\mathrm{n}=85$ \\
Digoxin & $\mathrm{n}=36$ \\
\hline
\end{tabular}

Abbreviations: ACEi, angiotensin-converting-enzyme inhibitor; ARB, angiotensin receptor blockers; HF, heart failure; NYHA, New York Heart Association. 
for individual statements included in the Polish adaptation of EHFScBS are presented in Table 3.

Cronbach's alpha characterizing internal consistency of the entire questionnaire was 0.64 . The values of Cronbach's alpha after deletion of specific items ranged from 0.55 to 0.65 . The highest values of item-total correlation were documented in the case of statements regarding contacting a doctor or nurse in the case of unexplained dyspnea or increased fatigue (statements no 3 and 8), and the lowest values for statements on having a rest during the day (statement no 7) or in the case of dyspnea (statement no 2). The detailed psychometric characteristics of the Polish adaptation of EHFScBS are presented in Table 4.

\section{Discussion}

The aim of this study was to adapt the EHFScBS to Polish conditions and to test the reliability of this instrument in a group of HF patients. The reliability testing was based on determining the routine psychometric characteristics of the scale, with Cronbach's alpha coefficient being a measure of its internal consistency. The internal consistency rate of this Polish adaptation of EHFScBS was 0.64. Therefore, this value was lower than both the internal consistency rate of the original instrument $(0.81),{ }^{9}$ and the values documented in validation studies of other language versions and cultural adaptations, conducted in Italy $(0.82),{ }^{15}$ the USA $(0.80),{ }^{14}$ Germany (0.71), ${ }^{13}$ Japan (0.71), ${ }^{12}$ Brazil $(0.70),{ }^{20}$ and the UK (0.69). ${ }^{16}$ However, two issues should be considered during interpretation of this finding: diagnostic accuracy of an instrument with an internal consistency rate slightly above $60 \%$ and the reasons for which the psychometric characteristics of this Polish adaptation of EHFScBS were worse than those of other language versions and cultural adaptations.
The answer to the first question is not simple, as a cutoff value for Cronbach's alpha, which would discriminate between instruments with sufficient and insufficient internal consistency rates, has not been defined in psychometric studies. According to some authors, the values of Cronbach's alpha $\geq 0.90$ should be considered as optimal, $\geq 0.80$ as good, $\geq 0.70$ as acceptable, $\geq 0.60$ as questionable, $\geq 0.50$ as poor, and $<0.50$ as unacceptable. ${ }^{21}$ Therefore, the Polish adaptation of EHFScBS should be considered as an instrument with limited value in this context. However, some researchers, especially from the field of social sciences, suggested that instruments with internal consistency rates of at least 0.6 should not be disqualified as long as the results are interpreted cautiously and within the whole sociodemographic context. ${ }^{22}$

The latter statement likely applies to our adaptation of EHFScBS, as detailed analysis of scores and psychometric characteristics of its individual statements identified potential reasons for discrepancies between the Polish instrument and other language versions and cultural adaptations. On the basis of results documented in our group of patients, the statements included in the questionnaire can be classified at three levels of self-care quality: 1) optimal - regarding adherence to doctor's prescriptions and behaviors enforced by a natural history of the disease; 2) moderate or poor-regarding lifestyle of the respondents; and 3) very poor - associated with seeking immediate help from medical personnel. Most of the respondents declared having a rest during the day or whenever necessary, eg, in the case of shortness of breath, and adhering to the prescribed therapeutic regimen. While the two first behaviors were evidently forced by the health status of our patients, the third one seems to reflect a role of the physician in Polish culture, in which this profession is

Table 3 Scores for individual items included in Polish adaptation of the EHFScBS questionnaire and the number of participants presenting with low levels of self-care (scores of 3-5 on the Likert scale) in domains characterized by the individual statements

\begin{tabular}{|c|c|c|c|}
\hline Item & Mean \pm SD & Median (IQR) & Inadequate $(n)$ \\
\hline I. I weigh myself every day. & $3.5 \pm 1.4$ & $4(3-5)$ & 76 \\
\hline 2. If I get short of breath I take it easy. & $1.6 \pm 1.2$ & $I(I-I)$ & 17 \\
\hline 3. If my shortness of breath increases I contact my doctor or nurse. & $2.9 \pm 1.6$ & $3(1-5)$ & 53 \\
\hline 4. If my feet/legs become more swollen than usual I contact my doctor or nurse. & $2.9 \pm 1.7$ & $3(1-5)$ & 53 \\
\hline 5. If I gain 2 kilo in one week I contact my doctor or nurse. & $3.8 \pm 1.5$ & $5(3-5)$ & 75 \\
\hline 6. I limit the amount of fluids I drink (not more than $1 \frac{1}{2}-2 \mathrm{~L} /$ day). & $2.8 \pm 1.6$ & $3(1-4)$ & 54 \\
\hline 7. I take a rest during the day. & $1.9 \pm 1.4$ & $I(I-3)$ & 26 \\
\hline 8. If I experience increased fatigue I contact my doctor or nurse. & $3.3 \pm 1.6$ & $4(2-5)$ & 64 \\
\hline 9. I eat a low salt diet. & $2.5 \pm 1.5$ & $2(1-4)$ & 41 \\
\hline I0. I take my medication as prescribed. & $1.6 \pm 1.3$ & $I(I-I)$ & 17 \\
\hline II. I get a flu shot every year. & $4.2 \pm 1.5$ & $5(4-5)$ & 82 \\
\hline 12. I exercise regularly. & $3.3 \pm 1.6$ & $3(2-5)$ & 65 \\
\hline
\end{tabular}

Notes: Adapted from Jaarsma T, Arestedt KF, Martensson J, Dracup K, Stromberg A. The European Heart Failure Self-care Behaviour scale revised into a nine-item scale (EHFSCB-9): a reliable and valid international instrument. Eur J Heart Fail. 2009; II(I):99-105. Published on behalf of the European Society of Cardiology. All rights reserved. Copyright @ 2009 Jaarsma T, Arestedt KF, Martensson J, Dracup K, Stromberg A. ${ }^{24}$

Abbreviations: EHFScBS, European Heart Failure Self-care Behavior Scale; IQR, interquartile range; SD, standard deviation. 
Table 4 Psychometric characteristics of Polish adaptation of the EHFScBS questionnaire

\begin{tabular}{lll}
\hline Item (Cronbach's alpha =0.64) & $\begin{array}{c}\text { Corrected } \\
\text { item-total } \\
\text { correlation }\end{array}$ & $\begin{array}{c}\text { Cronbach's } \\
\text { alpha if item } \\
\text { deleted }\end{array}$ \\
\hline I. I weigh myself every day. & 0.27 & 0.62 \\
2. If I get short of breath I take it easy. & 0.03 & 0.65 \\
3. If my shortness of breath increases I contact my doctor or nurse. & 0.59 & 0.55 \\
4. If my feet/legs become more swollen than usual I contact my doctor or nurse. & 0.43 & 0.58 \\
5. If I gain 2 kilo in one week I contact my doctor or nurse. & 0.32 & 0.6 I \\
6. I limit the amount of fluids I drink (not more than I I/2-2 L/day). & 0.27 & 0.62 \\
7. I take a rest during the day. & 0.08 & 0.65 \\
8. If I experience increased fatigue I contact my doctor or nurse. & 0.55 & 0.56 \\
9. I eat a low salt diet. & 0.36 & 0.60 \\
I0. I take my medication as prescribed. & 0.07 & 0.65 \\
II. I get a flu shot every year. & 0.1 I \\
I2. I exercise regularly. & 0.23 & 0.64 \\
\hline
\end{tabular}

Notes: Adapted from Jaarsma T, Arestedt KF, Martensson J, Dracup K, Stromberg A. The European Heart Failure Self-care Behaviour scale revised into a nine-item scale (EHFScB-9): a reliable and valid international instrument. Eur J Heart Fail. 2009; I I (1):99-105. Published on behalf of the European Society of Cardiology. All rights reserved. Copyright (C) 2009 Jaarsma T, Arestedt KF, Martensson J, Dracup K, Stromberg A. ${ }^{24}$

Abbreviation: EHFScBS, European Heart Failure Self-care Behavior Scale.

traditionally considered as one of the so-called professions of public trust. Unfortunately, as a result of the current collapse of the Polish health care system (limited availability of health care services and resultant long waiting times for medical visits and markedly shortened duration of the latter), most physicians can no longer play the role of health educators.

The hereby documented deficits of self-care with regards to activities that require immediate medical or nursing consultation due to the signs of potential decompensation also reflect the poor condition of the Polish health care system; the patients are unlikely to seek this type of support in view of many months of waiting for routinely scheduled control visits. The same refers to the yearly flu vaccination; this vaccination is not reimbursed in Poland and its cost constitutes a marked burden for household budgets, especially in the case of older persons. Moreover, one should remember the still prevalent media speculations on the limited efficacy and safety of the flu vaccination. ${ }^{23}$ The abovementioned data suggests that not only cultural characteristics but also the socioeconomic conditions of a given country should be considered during adaptation of EHFScBS and other similar instruments.

Analysis of the psychometric characteristics for the individual statements included in EHFScBS suggests that the relatively lower internal consistency rate of the Polish version is mostly associated with the limited availability of health care services in Poland. The abovementioned hypothesis is supported by the high values of the item-total coefficients of correlation for variables determined by the availability of health care, and the weaker item-total correlations for patient-dependent variables.
It should be noted, however, that apart from the abovementioned "system-driven" deficits of self-care, our study identified a number of deficits that are evidently associated with inappropriate lifestyle, ie, lack of physical activity, proper diet, and regular weight control. It is noteworthy that all these behaviors can be modified by educational interventions included within the framework of holistic care, alas well as those offered by nursing personnel, and can to a large extent counteract the deficits of self-care that result from inefficacy of the public health care system.

\section{Conclusion}

The study showed that Polish HF patients present significant deficits of self-care, which are to a large extent associated with inefficacy of the public health care system. Therefore, apart from cultural characteristics, the socioeconomic context of a target population should also be considered during language adaptation of EHFScBS and interpretation of data obtained with this instrument. Development of the unique self-care scale, which reflects Poland's health care environment and cultural or socioeconomic characteristics, represents another option. However, from an international research perspective this seems not optimal since it limits the comparability across countries and cultures. Nevertheless, our findings suggest that a number of self-care-related behaviors may be optimized as a result of appropriate educational activities, as well as those of nursing personnel.

\section{Disclosure}

The authors report no conflicts of interest in this work. 


\section{References}

1. Dickstein K, Cohen-Solal A, Filippatos G, et al; ESC Committee for Practice Guidelines (CPG). ESC guidelines for the diagnosis and treatment of acute and chronic heart failure 2008: the Task Force for the diagnosis and treatment of acute and chronic heart failure 2008 of the European Society of Cardiology. Developed in collaboration with the Heart Failure Association of the ESC (HFA) and endorsed by the European Society of Intensive Care Medicine (ESICM). Eur J Heart Fail. 2008;10(10):933-989.

2. Rabelo ER, Aliti GB, Domingues FB, Ruschel KB, de Oliveira Brun A. What to teach to patients with heart failure and why: the role of nurses in heart failure clinics. Rev Lat Am Enfermagem. 2007;15(1): $165-170$.

3. Lee CS, Moser DK, Lennie TA, Riegel B. Event-free survival in adults with heart failure who engage in self-care management. Heart Lung. 2011;40(1):12-20.

4. Lainscak M, Blue L, Clark AL, et al. Self-care management of heart failure: practical recommendations from the Patient Care Committee of the Heart Failure Association of the European Society of Cardiology. Eur J Heart Fail. 2011;13(2):115-126.

5. Moser DK, Dickson V, Jaarsma T, Lee C, Stromberg A, Riegel B. Role of self-care in the patient with heart failure. Curr Cardiol Rep. 2012; 14(3):265-275.

6. Riegel B, Carlson B, Glaser D. Development and testing of a clinical tool measuring self-management of heart failure. Heart Lung. 2000; 29(1):4-15.

7. Riegel B, Jaarsma T, Strömberg A. A middle-range theory of self-care of chronic illness. ANS Adv Nurs Sci. 2012;35(3):194-204.

8. Connelly CE. An empirical study of a model of self-care in chronic illness. Clin Nurse Spec. 1993;7(5):247-253.

9. Jaarsma T, Stromberg A, Martensson J, Dracup K. Development and testing of the European Heart Failure Self-Care Behaviour Scale. Eur J Heart Fail. 2003;5(3):363-370.

10. Orem D. Nursing: Concepts of Practice. 5th ed. St Louis, MO: Mosby; 1995.

11. Gonzalez B, Lupon J, Parajon T, Urrutia A, Herreros J, Valle V. Aplicación de la escala europea de autocuidado en insuficiencia cardíaca (EHFScBS) en una unidad de insuficiencia cardíaca en España. [Use of the European Heart Failure Self-care Behaviour Scale (EHFScBS) in a heart failure unit in Spain]. Rev Esp Cardiol. 2006;59(2):166-170. Spanish.

12. Kato N, Ito N, Kinugawa K, Kazuma K. Validity and reliability of the Japanese version of the European Heart Failure Self-Care Behavior Scale. Eur J Cardiovasc Nurs. 2008;7(4):284-289.
13. Koberich S, Glattacker M, Jaarsma T, Lohrmann C, Dassen T. Validity and reliability of the German version of the 9-item European Heart Failure Self-care Behaviour Scale. Eur J Cardiovasc Nurs. 2013;12(2): 150-158.

14. Lee CS, Lyons KS, Gelow JM, et al. Validity and reliability of the European Heart Failure Self-care Behavior Scale among adults from the United States with symptomatic heart failure. Eur J Cardiovasc Nurs. 2013;12(2):214-218.

15. Pulignano G, Del Sindaco D, Minardi G, et al. Translation and validation of the Italian version of the European Heart Failure Self-care Behaviour Scale. J Cardiovasc Med (Hagerstown). 2010;11(7):493-498.

16. Shuldham C, Theaker C, Jaarsma T, Cowie MR. Evaluation of the European Heart Failure Self-care Behaviour Scale in a United Kingdom population. J Adv Nurs. 2007;60(1):87-95.

17. Sosnowska-Pasiarska B, Bartkowiak R, Wożakowska-Kapłon B, et al. Population of Polish patients participating in the Heart Failure Pilot Survey (ESC-HF Pilot). Kardiol Pol. 2013;71(3):234-240.

18. Brislin R. Back-translation for cross-cultural research. J Cross Cult Psychol. 1970;1:185-216.

19. Hair J, Anderson R, Tatham R, Black W. Analise fatorial. In: Hair J, Anderson R, Tatham R, Black W, eds. Analise Multivariada de Dados. Porto Alegre (RS): Bookman; 2005:89-127. Portuguese.

20. Feijó MK, Ávila CW, de Souza EN, Jaarsma T, Rabelo ER. Crosscultural adaptation and validation of the European Heart Failure SelfCare Behavior Scale for Brazilian Portuguese. Rev Lat Am Enfermagem. 2012;20(5):988-996.

21. Beaton D, Bombardier C, Guillemin F, Ferraz MB. Recommendations for the Cross-Cultural Adaptation of the DASH \& QuickDASH Outcome Measures. Toronto, Canada: Institute for Work \& Health; 2007. Available from: http://dash.iwh.on.ca/system/files/X-CulturalAdaptation2007.pdf. Accessed August 17, 2014.

22. Gliem J, Gliem R. Calculating, interpreting, and reporting Cronbach's alpha reliability coefficient for Likert-type scales. Midwest Researchto- Practice Conference in Adult, Continuing, and Community Education. October 8-10, 2003; Columbus, OH: pp82-pp88.

23. Caille-Brillet AL, Raude J, Lapidus N, De Lamballerie X, Carrat F, Setbon $M$. Trends in influenza vaccination behaviours - results from the CoPanFlu cohort, France, 2006 to 2011. Euro Surveill. 2013; 18(45):20628.

24. Jaarsma T, Arestedt KF, Martensson J, Dracup K, Stromberg A. The European Heart Failure Self-care Behaviour scale revised into a nineitem scale (EHFScB-9): a reliable and valid international instrument. Eur J Heart Fail. 2009;11(1):99-105.
Patient Preference and Adherence

\section{Publish your work in this journal}

Patient Preference and Adherence is an international, peer-reviewed, open access journal that focuses on the growing importance of patient preference and adherence throughout the therapeutic continuum. Patient satisfaction, acceptability, quality of life, compliance, persistence and their role in developing new therapeutic modalities and compounds to optimize

\section{Dovepress}

clinical outcomes for existing disease states are major areas of interest for the journal. This journal has been accepted for indexing on PubMed Central. The manuscript management system is completely online and includes a very quick and fair peer-review system, which is all easy to use. Visit http://www. dovepress.com/testimonials.php to read real quotes from published authors. 